Клиническая онкогематология. 2018;11(3):259-64

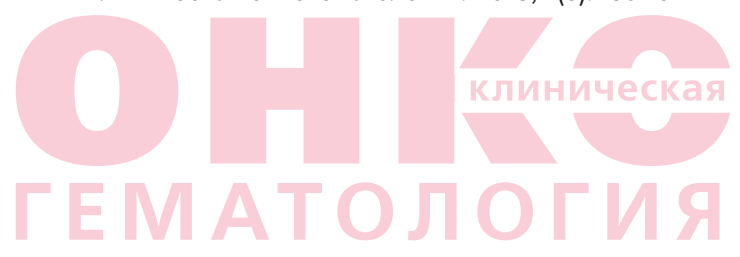

ИНФЕКЦИИ В ОНКОГЕМАТОЛОГИИ

\section{Aureobasidium pullulans-Associated Invasive Mycosis in a Child with Acute Myeloblastic Leukemia: A Case Report}

\author{
NS Bagirova', AV Popa', TS Bogomolova', \\ NA Batmanova', NV Dmitrieva', IN Petukhova', \\ ZV Grigor'evskaya ${ }^{1}, E^{2}$ Sokolova'
}

\author{
Н.С. Багирова', А.В. Попа', Т.С. Богомолова ${ }^{2}$, \\ Н.А. Батманова ${ }^{1}$, Н.В. Дмитриева ${ }^{1}$, И.Н. Петухова ${ }^{1}$, \\ 3.В. Григорьевская ${ }^{1}$, Е.Н. Соколова ${ }^{1}$
}

\begin{abstract}
1 ФГБУ «НМИЦ онкологии им. Н.Н. Блохина» Минздрава России, Каширское ш., д. 24, Москва, Российская Федерация, 115478

${ }^{2}$ ФГБОУ ВО «Северо-Западный государственный медицинский университет им. И.И. Мечникова» Минздрава России, ул. Кирочная, д. 41 , Санкт-Петербург, Российская Федерация, 191015
\end{abstract}

\section{РЕФЕРАТ}

Тяжелая микотическая инфекция, возникающая преимущественно у пациентов со сниженным иммунитетом, часто осложняет течение основного онкогематологического заболевания. Впервые в отечественной литературе мы представляем клинико-микробиологические особенности инвазивного микоза, обусловленного $\mathrm{Au-}$ reobasidium pullulans, у ребенка с острым миелобластным лейкозом, получавшего цитостатическую и противогрибковую терапию с благоприятным исходом.

Ключевые слова: Aureobasidium pullulans, острый миелобластный лейкоз, инвазивный микоз.

Получено: 15 января 2018 г.

Принято в печать: 8 апреля 2018 г.

Для переписки: Наталия Сергеевна Багирова, д-р мед. наук, Каширское ш., д. 24, Москва, Российская Федерация, 115478; тел.: 8(499)324-18-60; e-mail: nbagirova@mail.ru

Для цитирования: Багирова Н.С., Попа А.В., Богомолова Т.С. и др. Инвазивный микоз, обусловленный Aureobasidium pullulans, у ребенка с острым миелобластным лейкозом (собственное клиническое наблюдение). Клиническая онкогематология. 2018;11(3):259-64.

DOI: 10.21320/2500-2139-2018-11-3-259-264
${ }^{1}$ NN Blokhin National Medical Cancer Research Center, 24 Kashirskoye sh., Moscow, Russian Federation, 115478

${ }^{2}$ II Mechnikov North-Western State Medical University, 41 Kirochnaya str., Saint Petersburg, Russian Federation, 191015

\section{ABSTRACT}

Severe mycotic infection occurring mainly in immunocompromised patients often exacerbates the progression of the primary oncohematological disease. It is the first attempt in Russian literature to present clinical and microbiological characteristics of invasive mycosis caused by Aureobasidium pullulans in a child with acute myeloblastic leukemia after receiving cytoreductive and antifungal treatment with favourable outcome.

Keywords: Aureobasidium pullulans, acute myeloblastic leukemia, invasive mycosis.

Received: January 15, 2018

Accepted: April 8, 2018

For correspondence: Nataliya Sergeevna Bagirova, MD, PhD,

24 Kashirskoye sh., Moscow, Russian Federation, 115478;

Tel.: 8(499)324-18-60; e-mail: nbagirova@mail.ru

For citation: Bagirova NS, Popa AV, Bogomolova TS, et al. Aureobasidium pullulans-Associated Invasive Mycosis in a Child with Acute Myeloblastic Leukemia: A Case Report. Clinical oncohematology. 2018;11(3):259-64.

DOI: 10.21320/2500-2139-2018-11-3-259-264

\section{ОПИСАНИЕ КЛИНИЧЕСКОГО НАБЛЮДЕНИЯ}

Больная Д., 9 лет, заболела в марте 2015 г. При поступлении в НИИ ДОГ ФГБУ «НМИЦ онкологии им. Н.Н. Блохина» МЗ РФ 05.03.2015 г. был установлен диагноз острого миелобластного лейкоза (ОМЛ) с признаками созревания (М2-вариант по классификации FAB), 46,XX, промежуточная группа риска. При поступлении масса тела ребенка 29,5 кг, рост 125 см, площадь тела $1 \mathrm{~m}^{2}$; состояние тяжелое, в сознании, контактна. Кожные покровы бледные, выраженные геморрагический и лимфопролиферативный синдромы. 
С 13.03.2015 г. начато лечение по протоколу НИИ ДОГ ОМЛ 2012 (сочетание химио- и эпигенетической терапии), а также индукция ремиссии AIE (цитарабин, идарубицин, этопозид) с вальпроевой и полностью транс-ретиноевой кислотами, азацитидином на 16-й день от начала лечения.

На 15-й день после первого курса индукции ремиссии по схеме AIE по данным миелограммы был получен отчетливый противоопухолевый эффект. В результате терапии аплазия костного мозга IV степени сохранялась 30 дней, восстановление кроветворения отмечено к 35-му дню после окончания курса индукции ремиссии. По данным миелограммы от 17.04.2015 г. достигнута полная костномозговая ремиссия.

Постиндукционная терапия состояла из 3 курсов химиотерапии: НАM (27.04-30.04.2015 г.), AI (02.0606.06.2015 г.) и hАМ (09.07-12.07.2015 г.).

Первые два постиндукционных курса больная перенесла удовлетворительно, после каждого из них отмечалась фебрильная нейтропения, которая купировалась антибактериальной (цефепим, меропенем, линезолид) и противогрибковой терапией (вориконазол).

C 1-го дня 4-го курса химиотерапии hАM регистрировалась фебрильная температура $38,7{ }^{\circ} \mathrm{C}$, по поводу чего эмпирически был назначен линезолид по 10 мг/кг 3 раза в сутки (1-4-й день), и температура тела нормализовалась, что было расценено как эффективность антибактериальной терапии. С 6-го дня терапии на фоне аплазии костного мозга эмпирически добавлены пиперациллин/тазобактам 300 мг/кг/сут, разделенные на 3 приема, и амикацин 20 мг/кг/сут однократно, инфекционный синдром купирован. С Д+10 отмечалось возобновление лихорадки до 4 эпизодов в сутки. Добавлен ванкомицин по 40 мг/кг 4 раза в сутки без эффекта. С 25.07.2015 г. (Д+11) назначен пиперациллин/тазобактам 300 мг/кг/сут, разделенные на 3 приема, который был заменен на имипенем/циластатин 100 мг/кг/сут в 4 приема. С 26.07.2015 г. ванкомицин заменен на линезолид по 10 мг/кг 3 раза в сутки. Данные КТ органов грудной клетки от 27.07.2015 г.: картина двусторонней полисегментарной пневмонии. К антибактериальной терапии добавлен вориконазол по 200 мг в/в 2 раза в сутки. К 31.07.2015 г. отмечена положительная динамика в виде уменьшения эпизодов лихорадки до 2 раз в сутки, признаков дыхательной недостаточности, увеличения уровня лейкоцитов до $0,6 \times 10^{9}$ /л. Однако 3.08.2015 г. состояние вновь ухудшилось, что проявилось динамической кишечной непроходимостью, нарастанием интоксикации. 3.08.2015 г. вориконазол заменен на каспофунгин 70 мг/м²/сут в 1-й день и далее в дозе 50 мг/м²/сут. Антибактериальная терапия усилена метронидазолом 35 мг/кг/сут, разделенные на 3 приема. Линезолид, амикацин, вориконазол отменены. Проводилась трансфузия внутривенного иммуноглобулина 0,5 мг/кг, стимуляция кишечника. Проявления пареза кишечника купированы. На фоне лихорадки (4 эпизода в сутки с подъемом температуры тела до $38^{\circ} \mathrm{C}$ и выше) 6.08.2015 г. добавлен линезолид по 10 мг/кг 3 раза в сутки.

При отсутствии какой-либо динамики по данным КТ органов грудной клетки от 4.08.2015 г. при УЗИ органов брюшной полости 6.08.2015 г. в печени вы- явлены множественные анэхогенные образования 0,2-0,3 см в диаметре, расположенные равномерно, как в правой, так и левой доле органа. Продолжена противогрибковая терапия, имипенем/циластатин отменены. Отмечалось восстановление гематологических показателей, сохранение лихорадки до 3 эпизодов в сутки. 12.08.2015 г. проведена трансфузия иммуноглобулина 0,5 г/кг/сут. При КТ органов грудной клетки 11.08.2015 г. наблюдалась незначительная положительная динамика в виде уплотнения очагов в легких, частичной их регрессии. В то же время отмечена отрицательная динамика в виде распространения инфекционных очагов по паренхиматозным органам. Так, по данным УЗИ органов брюшной полости 13.08.2015 г. увеличились количество и размеры (до 3-5 мм) гипоэхогенных очагов в печени. Кроме того, наблюдалось появление таких же очагов в селезенке (до 4 мм), некоторые из них имели гиперэхогенный центр в виде погремушки. В связи с отрицательной динамикой 13.08.2015 г. было решено провести смену эмпирической противогрибковой терапии. Отменены каспофунгин и метронидазол, назначен вориконазол 8 мг/кг 2 раза в сутки. Тем не менее сохранялась лихорадка до 4-5 эпизодов в сутки с подъемом температуры тела до $38{ }^{\circ} \mathrm{C}$ и выше. 19.08.2015 г. эмпирически назначена липидная форма амфотерицина В 1 мг/кг в/в (30 мг/сут), вориконазол отменен.

Несмотря на проводимую терапию, по данным контрольных исследований наблюдалась отрицательная динамика (Д+38 от начала hАM). УЗИ органов брюшной полости от 20.08.2015 г.: увеличение количества очагов в селезенке, а также их размеров (до 6 мм). В печени по данным УЗИ картина прежняя. КТ органов грудной клетки от 21.08.2015 г.: по сравнению с предыдущим исследованием определяется положительная динамика в виде уменьшения размера и количества очагов в легких. УЗИ органов брюшной полости от 27.08.2015 г.: дальнейшее увеличение количества очагов в паренхиме печени и селезенки, а также появление подобных очагов в правой почке (субкапсулярно в корковом веществе единичные очаги до 3 мм). На фоне эмпирической антимикробной терапии сохранялось 3 эпизода фебрильной температуры ( $\left.\geq 38^{\circ} \mathrm{C}\right)$ в день, была периодическая рвота. Уровень прокальцитонина в пределах нормы. Учитывая, что положительная динамика по данным КТ связана преимущественно с применением вориконазола, было решено усилить противогрибковую терапию. Вориконазол продолжен по 9 мг/кг в/в 2 раза в сутки.

КТ органов грудной клетки от 2.09.2015 г.: легочный рисунок значительно усилен и деформирован. По сравнению с исследованием от 21.08.2015 г. без существенной динамики. С 20.09.2015 г. отмечается прекращение лихорадки. КТ органов грудной клетки от 17.09.2015 г.: состояние органов грудной полости без динамики по сравнению с исследованием от 2.09.2015 г. УЗИ органов брюшной полости от 14.09.2015 г.: умеренная положительная динамика в виде уменьшения размеров инфекционных очагов в печени. Учитывая положительную динамику в результате противогрибковой терапии вориконазолом, отсутствие лихорадки, уменьшение инфильтрации легочной ткани и размеров гипоэхогенных очагов в 
печени, отсутствие эпизодов фебрильной лихорадки, девочка выписана 21.09.2015 г. из стационара с рекомендацией принимать вориконазол внутрь в капсулах 9 мг/кг 2 раза в сутки. Амбулаторно при приеме вориконазола внутрь вновь появилась фебрильная температура до 2 эпизодов в сутки, и 9.10.2015 г. больная была госпитализирована для продолжения противогрибковой терапии внутривенно.

Сохраняется положительная динамика со стороны инфильтративных очагов в легких (уменьшение объема и количества). По данным УЗИ органов брюшной полости от 19.10.2015 г. динамики не отмечено. При МРТ органов брюшной полости с внутривенным контрастированием от 23.11.2015 г. (рис. 1): в печени, селезенке, почках, легких определялись множественные кольцевидные паренхиматозные очаги с включениями высокобелковой жидкости в центре (некроз?) 0,2-1,1 см в диаметре, сливающиеся между собой, не накапливающие контрастный препарат. Заключение: выявленные изменения в печени, селезенке, почках, обоих легких, на брюшине (?) не противоречат поражению при микозе.

Учитывая отсутствие положительной динамики, 1.12.2015 г. в диагностической и лечебной целях выполнены лапароскопия, ревизия брюшной полости, лапаротомия, спленэктомия, дренирование брюшной полости. Селезенка резко увеличена $(14 \times 7 \times 6$ см) (рис. 2). На разрезе видны множественные очаги зеленовато-белого цвета различного размера как в паренхиме органа, так и под капсулой. Селезенка поражена воспалительными очагами полностью. Расстояние между очагами не превышает 2 см.

Биоматериал из очагов некроза в ткани селезенки 2.12.2015 г. был отправлен в лабораторию микробиологии. При микроскопии мазков-отпечатков из очагов некроза селезенки обнаружены в большом количестве септированные гифы, группы бластоконидий, образующихся от гиф синхронно (рис. 3).

При посеве присланного материала на искусственные питательные среды (5\% кровяной агар, агары Сабуро, шоколадный, Эндо, желточно-солевой, жидкий сердечно-мозговой экстракт) при $37^{\circ} \mathrm{C}$ роста не получено, но при температуре $30{ }^{\circ} \mathrm{C}$ через сутки на агаре Сабуро получен рост мелких, чуть различимых пушистых колоний. В течение последующих суток вид колоний постепенно менялся от белых до розоватосерых, а затем темно-коричневых или черных (рис. 4).

При микроскопии мазка из чистой 12-суточной культуры A. pullulans, окрашенного по Граму, видны недифференцированные конидиеносцы, которые расположены интеркалярно или терминально и выглядят как короткие боковые ветви (рис. 5). Эндоконидии образуются интеркалярно и высвобождаются в соседнюю пустую клетку. Гифы гиалиновые, гладкие, тонкостенные, с поперечными перегородками.

Следует отметить, что больной до спленэктомии 9 раз проводилось микробиологическое исследование крови с целью выявить бактериемию при каждом эпизоде лихорадки. Посев выполняли 1-2 раза в течение каждого эпизода лихорадки, но роста получить не удалось. После спленэктомии посев крови проведен 4 раза однократно в течение суток, роста также не получено.

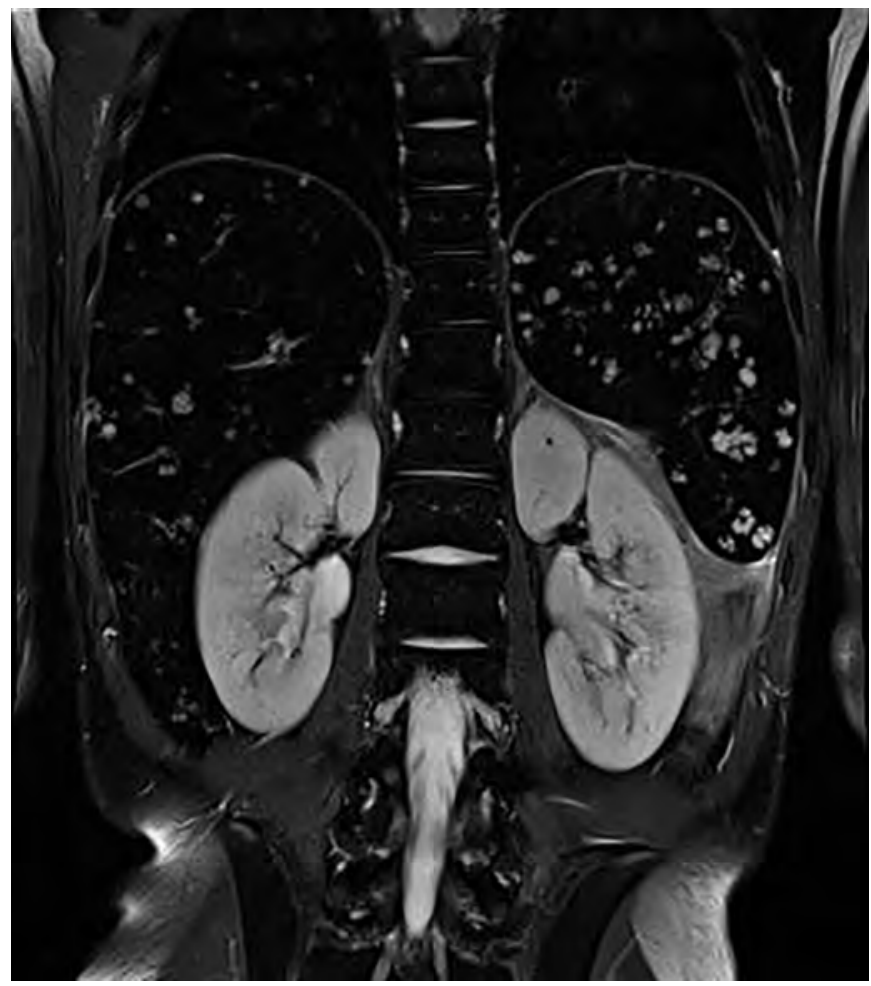

Рис. 1. Больная Д., 9 лет, М2-вариант ОМЛ, инвазивный микоз. МРТ всего тела от 23.11.2015 г. Множественные воспалительные очаги в печени, селезенке и почках различных размеров (фото любезно предоставлено А.В. Попой)

Fig. 1. A 9-year-old female patient, AML, M2 type, invasive mycosis. Whole-body MRI (November 23, 2015). Multiple inflammatory lesions of various sizes in the liver, spleen, and kidneys (photograph courtesy of A.V. Popa)

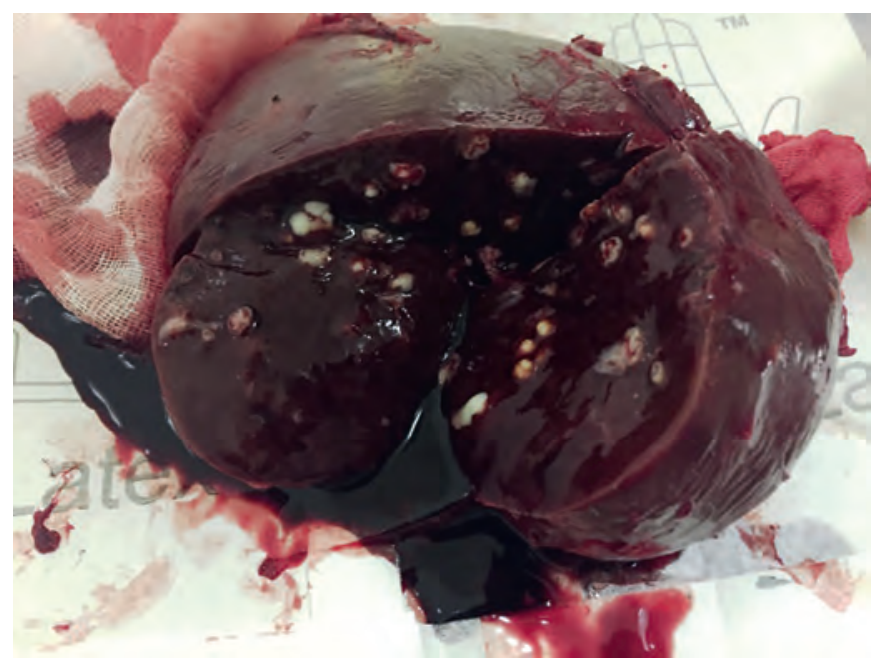

Рис. 2. Макроскопический препарат удаленной селезенки (фото любезно предоставлено А.В. Попой)

Fig. 2. Macroscopic sample of the removed spleen (photograph courtesy of A.V. Popa)

Послеоперационный период протекал без осложнений. Со 2.12.2015 г. проводилась противогрибковая терапия вориконазолом по 200 мг в/в капельно 2 раза в сутки, а также антибактериальная терапия. C 4.12.2015 г. назначены липидная форма амфотерицина В 5 мг/кг в/в капельно 1 раз в сутки (разовая доза 100 мг) до 14.12.2015 г., цефазолин 100 мг/кг/сут в/в струйно, разделенные на 3 введения, в течение 7 дней, 

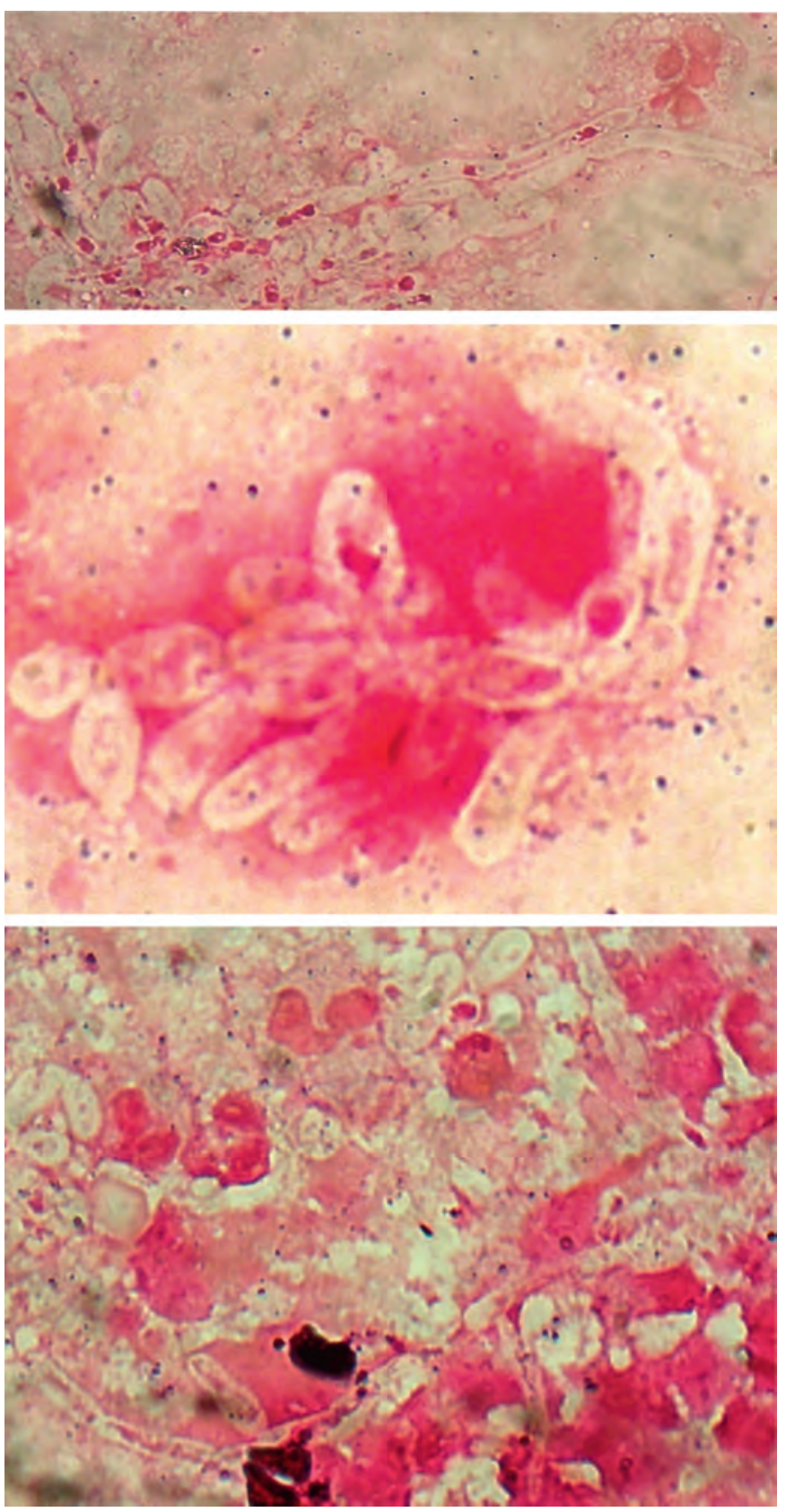

Рис. 3. Больная Д., 9 лет. Лапароскопия. Спленэктомия. Мазкиотпечатки из очагов некроза в селезенке. Окраска по Граму, иммерсия, ×1000 (фото любезно предоставлены Н.С. Багировой)

Fig. 3. A 9-year-old female patient. Laparoscopy and splenectomy. Imprint smears from necrotic lesions in the spleen. Gram stain, immersion, $\times 1000$ (photographs courtesy of N.S. Bagirova)

инфузионная терапия, частичное парентеральное питание, трансфузии иммуноглобулина, альбумина.

В дальнейшем больная получала монотерапию вориконазолом по 9 мг/кг в/в 2 раза в сутки до 8.02.2016 г. Отмечалась положительная динамика в виде сокращения количества эпизодов фебрильной температуры до 1 раза в сутки. Уменьшение количества и размера инфекционных очагов в печени не наблюдалось. С 9.02.2016 по 23.02.2017 г. пациентка получала вориконазол внутрь по 9 мг/кг 2 раза в сутки. В результате проводимого лечения отмечалось постепенное сокращение количества и размера очагов в печени, исчезновение воспалительных очагов в паренхиме почек, а с 15.01.2017 г. эпизоды лихорадки

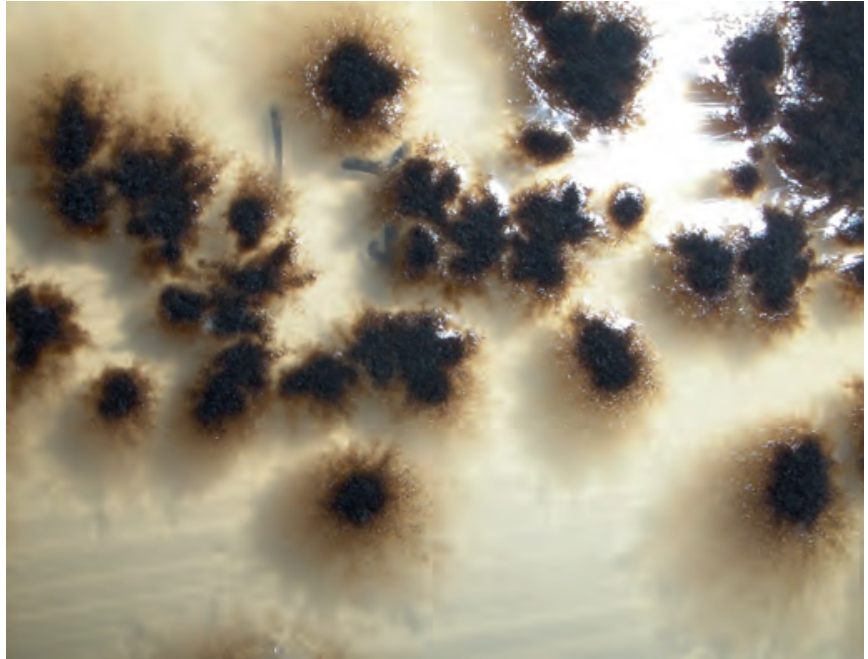

Рис. 4. Больная Д., 9 лет. Рост колоний Aureobasidium pullulans на агаре Сабуро при температуре $30{ }^{\circ} \mathrm{C}$ (фото любезно предоставлено Н.С. Багировой)

Fig. 4. A 9-year-old female patient. Aureobasidium pullulans colony growth on Sabouraud agar at the temperature of $30^{\circ} \mathrm{C}$ (photograph courtesy of N.S. Bagirova)

прекратились. По данным УЗИ органов брюшной полости гипоэхогенные очаги в печени не обнаруживались с февраля 2017 г.

У больной постепенно стал улучшаться аппетит, к маю 2017 г. масса тела составила 35 кг, что соответствовало возрасту. В результате проведенного лечения больная находится в полной клинико-гематологической ремиссии по основному заболеванию (ОМЛ) и излечена от инвазивного микоза.

\section{ОБСУЖДЕНИЕ}

A. pullulans - это повсеместно распространенный микроорганизм (сапрофит), имеющий медицинское и сельскохозяйственное значение, он также имеет биотехнологическое применение. A. pullulans обнаруживают не только в воздухе и на природных объектах окружающей среды (листья растений, камни, поверхности деревьев, стены зданий, поверхности памятников), но и на различных поверхностях объектов жилых и больничных помещений (деревянные, стеклянные, металлические, синтетические) $[1,2]$.

A. pullulans редко вызывают инфекцию у людей (возбудитель феогифомикоза, в т. ч. легочных форм). Первый случай висцерального микоза, вызванного $A$. pullulans, был представлен в зарубежной литературе в 1986 г. [3]. К настоящему времени описано немногим более 30 случаев феогифомикоза у человека, обусловленного A. pullulans [4].

Инвазивный микоз, вызванный A. pullulans, зачастую трудно поддается лечению. Стандартная терапия отсутствует. По данным зарубежной литературы, хорошая противогрибковая активность в отношении A. pullulans in vitro отмечается у вориконазола и итраконазола $[1,2]$. До недавнего времени не было систематических данных о чувствительности A. pullulans к противогрибковым средствам. В исследовании 

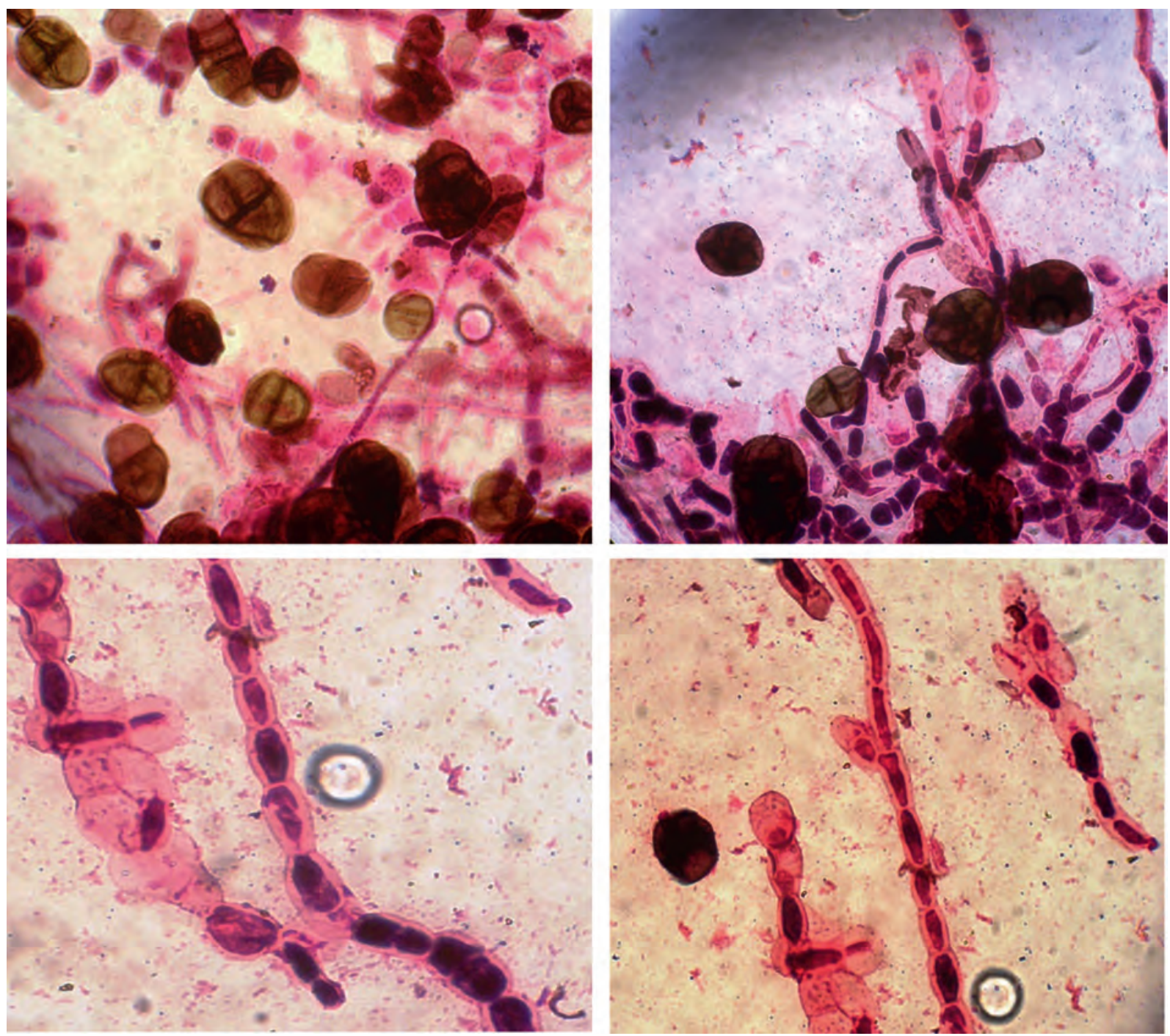

Рис. 5. Больная Д., 9 лет. Чистая 12-суточная культура Aureobasidium pullulans. Мазок, окраска по Граму, иммерсия, ×1000 (фото любезно предоставлены Н.С. Багировой)

Fig. 5. A 9-year-old female patient. 12-day Aureobasidium pullulans stock culture. Smear, Gram stain, immersion, $\times 1000$ (photographs courtesy of N.S. Bagirova)

M.J. Najafzadeh и соавт. [4] изучена чувствительность 104 штаммов A. pullulans (51 штамм из клинического материала) после идентификации на молекулярногенетическом уровне. Амфотерицин В, итраконазол и позаконазол были признаны препаратами с наилучшей активностью против A. pullulans. Длительная терапия при инфекциях, вызываемых подобными грибами, обычно колеблется от нескольких недель до нескольких месяцев или более. Кроме того, больной должен получать адекватное питание и инфузионную терапию, т. к. общая воспалительная реакция при тяжелых инвазивных микозах приводит к тяжелому и довольно быстрому истощению ребенка. Потеря более 10-15 \% массы тела может оказаться необратимой и фатальной.

Представленное наблюдение демонстрирует развитие инвазивного микоза, обусловленного редким видом микромицетов. В качестве терапии микоза, вызванного A. pullulans, определен ограниченный набор противогрибковых препаратов: итраконазол, вориконазол и амфотерицин В. К сожалению, амфотерицин В достаточно нефротоксичен, к тому же трудно достичь его высокой концентрации в тканях.
В нашем случае пациентка получала амфотерицин В (липидную форму) в течение 10 дней. В дальнейшем был назначен вориконазол в течение длительного времени. Терапия вориконазолом была продолжена и после спленэктомии.

Таким образом, было достигнуто полное излечение от инвазивного микоза редкой этиологии, а также полная клинико-гематологическая ремиссия по основному заболеванию (ОМЛ).

\section{ЗАКЛЮЧЕНИЕ}

Сложность лечения онкогематологических больных обусловлена несколькими факторами. Во-первых, лечение основного онкогематологического заболевания почти всегда сопровождается симптомами, которые трудно отличить от инфекционных. Во-вторых, при подозрении на инфекционное осложнение в процессе лечения основного заболевания системы крови врач зачастую вынужден назначать эмпирическую терапию, которая не всегда оказывается адекватной. В-третьих, при назначении противогрибковой те- 
рапии врач прежде всего ориентируется на наиболее вероятных возбудителей. Однако в последние годы спектр грибковых патогенов стремительно расширяется. Данных для разработки рекомендаций по лечению подобных инфекций еще недостаточно. В связи с этим исключительно важное значение приобретает проблема выбора адекватной противогрибковой терапии.

\section{КОНФЛИКТЫ ИНТЕРЕСОВ}

Авторы заявляют об отсутствии конфликтов интересов. А.В. Попа, член редакционной коллегии журнала «Клиническая онкогематология. Фундаментальные исследования и клиническая практика», не принимал участия в рецензировании рукописи.

\section{ИСТОЧНИКИ ФИНАНСИРОВАНИЯ}

Исследование не имело спонсорской поддержки.

\section{ВКЛАД АВТОРОВ}

Концепция и дизайн: Н.С. Багирова.

Сбор и обработка данных: все авторы.

Предоставление материалов исследования: Н.С. Багирова, А.В. Попа, Н.А. Батманова.

Анализ и интерпретация данных: Н.С. Багирова, А.В. Попа, Т.С. Богомолова.

Подготовка рукописи: Н.С. Багирова, А.В. Попа.

Окончательное одобрение рукописи: все авторы.

\section{ЛИTEPATYPA/REFERENCES}

1. Revankar SG, Sutton DA. Melanized Fungi in Human Disease. Clin Microbiol Rev. 2010;23(4):884-928. doi: 10.1128/CMR.00019-10.

2. Hussain N, Revankar SG. Black Mold Infections: What We Know and What We Need to Know. Curr Clin Microbiol Rpt. 2017;4(2):106-11. doi: 10.1007/s40588017-0062-x.

3. Salkin IF, Martinez JA, Kemna ME. Opportunistic infection of the spleen caused by Aureobasidium pullulans. J Clin Microbiol. 1986;23(5):828-31.

4. Najafzadeh MJ, Sutton DA, Keisari MS, et al. In Vitro Activities of Eight Antifungal Drugs against 104 Environmental and Clinical Isolates of Aureobasidium pullulans. Antimicrob. Agents Chemother. 2014;58(9):5629-31. doi: 10.1128/ AAC.03095-14. 